\title{
ANALISIS KONTRASTIF KALIMAT PASIF BAHASA INDONESIA DENGAN BAHASA INGGRIS
}

\author{
Djuria Suprato \\ English Literature Department, Faculty of Humanities, BINUS University \\ Jln. Kemanggisan Ilir III No. 45, Kemanggisan - Palmerah, Jakarta Barat 11480 \\ sdjuria@yahoo.com
}

\begin{abstract}
The difficulty of a teacher to teach a second language to students can be addressed by contrastive analysis, where it is assumed that learning a second language is influenced by the first language acquisition. The purpose of this article is to describe the level of a comparable degree of passive sentences in Indonesian and English to provide benefits as a reference in the teaching of English as a second language. This study was conducted with qualitative methods, the reference library of resources Indonesian and English. Passive Sentences in Indonesian views of the structure using the "di", "ter" or "ke", in English we use "to be + past participle" depends on the time it happened. Context of the sentence must be considered so that the meaning contained in them can be understood. Once analyzed and searched in the matching and comparison of passive sentences in Indonesian and English, the authors have found similarities and differences which can be structurally or pragmatically.
\end{abstract}

Keywords: contrastive analysis, comparison, active and passive sentence

\begin{abstract}
ABSTRAK
Kesulitan seorang guru mengajarkan bahasa kedua kepada para siswa dapat diatasi dengan analisis kontrastif, di mana diasumsikan bahwa dalam mempelajari bahasa kedua dipengaruhi oleh penguasaan bahasa pertama. Tujuan artikel ini adalah untuk mendeskripsikan tingkat perbandingan kalimat pasif bahasa Indonesia dan Bahasa Inggris yang dapat memberikan manfaat sebagai acuan dalam pengajaran bahasa Inggris sebagai bahasa kedua. Penelitian dilakukan dengan metode kualitatif, dengan acuan pustaka dari sumber Bahasa Indonesia dan bahasa Inggris. Kalimat pasif dalam bahasa Indonesia dilihat dari strukturnya menggunakan "di-", "ter-" ataupun "ke-". Sementara dalam bahasa Inggris hanya mengenal "to be+ past participle" yang tergantung waktu kejadiannya (sesuai tenses). Konteks kalimat harus diperhatikan sehingga makna terkandung di dalamnya benar-benar dapat dimengerti. Setelah dianalisis dan dicari padanan dan perbandingannya dalam kalimat pasif dalam bahasa Indonesia dan Bahasa Inggris, penulis telah menemukan persamaan dan perbedaan yang ada. Baik persamaan maupun perbedaannya dapat dilihat secara struktural maupun secara pragmatis.
\end{abstract}

Kata kunci: analisis kontrastif, perbandingan, kalimat pasif dan aktif 


\section{PENDAHULUAN}

Dalam keseharian bila kita perhatikan dengan saksama, sebagai seorang guru atau calon guru yang mengajarkan bahasa Indonesia, kita akan menemukan kesalahan-kesalahan yang dibuat oleh para siswa. Kesalahan-kesalahan itu ternyata dapat kita bedakan dalam dua kategori, yaitu kategori kesalahan dalam bidang keterampilan dan kesalahan dalam bidang linguistik. Kesalahan yang berhubungan dengan keterampilan terjadi pada saat siswa menyimak, berbicara, membaca, dan menulis. Sedangkan kesalahan dalam bidang linguistik meliputi tata bunyi, tata bentuk kata, dan tata kalimat.

Guru sering menghadapi kesulitan dalam mengajarkan bahasa kedua kepada para siswanya. Untuk itu guru harus mengenal analisis kontrastif. Analisis ini dapat membantu guru bahasa menolong dan sekaligus memperbaiki kesalahan siswa. Dengan demikian, para siswa dapat segera menguasai bahasa sasaran (B2) yang dipelajari. Analisis kontrastif sebagai suatu pendekatan pengajaran bahasa mengasumsikan bahwa $\mathrm{Bl}$ memengaruhi siswa ketika mempelajari B2.

Analisis kontrastif adalah aktivitas atau kegiatan yang mencoba membandingkan struktur bahasa pertama (B1) dengan struktur bahasa kedua (B2) untuk mengidentifikasi perbedaan-perbedaan di antara kedua bahasa. Perbedaan-perbedaan antara dua bahasa, yang diperoleh dan dihasilkan melalui Anakon, dapat digunakan sebagai landasan dalam meramalkan atau memprediksi kesulitankesulitan atau kendala-kendala belajar berbahasa yang akan dihadapi oleh para siswa di sekolah, terlebih dalam belajar B2.

Analisis kontrastif dapat menolong guru bahasa dan siswa yang sedang mempelajari bahasa kedua agar segera menguasai bahasa sasaran tersebut dengan baik. Analisis kontrastif terbatas hanya menganalisis dua bahasa dengan jalan membandingkannya, yakni membandingkan bahasa kedua dengan bahasa pertama atau antara bahasa yang dipelajari dengan bahasa ibu. Hasil perbandingan unsur kebahasaan yang berbeda akan membantu guru bahasa untuk meramalkan kesalahan yang kemungkinan dilakukan siswa dan sekaligus menolong siswa agar segera menguasai bahasa sasaran (B2).

Masalah yang dirumuskan dalam penelitian ini adalah: (1) Bagaimana kalimat pasif dalam Bahasa Indonesia, (2) Bagaimana kalimat pasif dalam Bahasa Inggris, (3) Bagaimana perbandingan kalimat pasif dalam Bahasa Indonesia dan Bahasa Inggris.

Dalam penelitian ini penulis membatasi kajian penelitian dengan berfokus pada kalimatkalimat yang ada dalam buku Understanding and Using English Grammar karangan Betty Schrampfer Azar dan Teori Terjemahan dan Kaitannya dengan Tata Bahasa Inggris dalam Bahasa Indonesia karangan Sofia Rangkuti Hasibuan serta Tata Bahasa Baku Indonesia karangan Hasan Alwi, dkk. Hasil penelitian tersebut dirangkum dalam artikel singkat ini yang difokuskan pada analisis kontrastif kalimat pasif dalam bahasa Indonesia dan bahasa Inggris.

\section{METODE PENELITIAN}

Penelitian ini dilakukan dengan mencari sumber teori mengenai kalimat dan jenis-jenis kalimat. Kemudian difokuskan pada kalimat pasif baik bentuk tata bahasa dalam bahasa Inggris maupun dalam Bahasa Indonesia. Kedua bentuk dan makna kalimat pasif tersebut dibandingkan dan dianalisis perbedaannya. Semua ini dilakukan dengan metode kualitatif dengan teknik analisis isi yang terdiri dari kalimat pasif bahasa Indonesia dan bahasa Inggris. 
Tujuan penulisan penelitian ini adalah untuk mendeskripsikan tingkat perbandingan kalimat pasif dalam bahasa Indonesia dan Bahasa Inggris. Hasil penelitian ini diharapkan dapat memberikan manfaat yang dapat dijadikan acuan bagi pengajaran Bahasa Inggris pada umumnya dan khususnya berkaitan dengan kalimat pasif.

Manfaat yang dimaksud adalah diharapkan dapat dijadikan model penelitian guna meningkatkan keterampilan berbahasa, khususnya yang berkaitan dengan kalimat pasif dalam bahasa Inggris. Hasil penelitian ini juga diharapkan dapat dijadikan acuan oleh pengajar bahasa dalam menentukan model pemecahan masalah yang berkaitan dengan pengajaran di kelas, khususnya kalimat pasif. Penelitian ini diharapkan pula dapat membuka wawasan penulis dan mahasiswa lain pada pengetahuan Bahasa Inggris khususnya tentang kalimat pasif dalam bahasa Indonesia dan Bahasa Inggris. Manfaat teoritis dari penelitian ini adalah untuk mengembangkan ilmu pendidikan bahasa terutama pada aspek pengajaran grammar atau tata bahasa khususnya kalimat pasif dalam bahasa Indonesia dan bahasa Inggris.

\section{HASIL DAN PEMBAHASAN}

Pengajaran Bahasa Inggris tidak lepas dari pengajaran tata bahasa atau disebut juga dengan grammar. Dalam pengajaran Bahasa Inggris untuk siswa pada umumnya mencakup empat keterampilan bahasa yaitu menyimak (listening), berbicara (speaking), membaca (reading), dan menulis (writing) dan untuk pengajaran tata bahasa atau grammar tidak secara tersurat tercakup dalam kurikulum keempat keterampilan tersebut. Meskipun demikian, pengajaran grammar menjadi suatu kesatuan dalam pengajaran keempat keterampilan di atas.

Oleh karena itu, menjadi suatu pertanyaan bagi pengajar apakah masih perlu mengajar tata bahasa pada aspek pengajaran bahasa Inggris. Dengan kesan bahwa pengajaran grammar ini tidak menarik, baik bagi siswa maupun guru. Beberapa guru mencoba dengan berbagai teknik dalam pengajaran grammar ini, tetapi masih saja mengalami kesulitan dalam memberi pemahaman kepada siswa.

Salah satu materi grammar yang sangat sulit dipahami oleh siswa adalah kalimat pasif. Siswa diajarkan kalimat pasif setelah mereka mengerti kalimat aktif. Dalam bukunya Pedoman Penerjemahan, Bagaimana Menerjemahkan Bahasa Inggris ke dalam Bahasa Indonesia, Sutinah Suwondo (1994) menyatakan bahwa secara umum dalam bahasa Inggris dapat kita bedakan dalam empat jenis kalimat, yaitu (1) kalimat berita, (2) kalimat tanya, (3) kalimat perintah, dan (4) kalimat seru. Di antara empat jenis kalimat universal tersebut yang paling banyak dipakai dalam buku-buku dan tulisan-tulisan ilmiah adalah kalimat berita (= statement) dalam berbagai bentuknya, seperti: kalimat positif dan negatif, kalimat aktif dan pasif, kalimat langsung dan tidak langsung, kalimat biasa dan pengandaian, kalimat sederhana, majemuk dan kompleks. Semua kalimat itu hanya dapat dipahami dengan baik sesuai dengan bentuk-bentuknya yang berkaitan dengan waktu, kapan tindakan yang terkandung dalam kalimat itu terjadi, yang dalam bahasa Inggris disebut tenses.

Untuk menjelaskan kalimat pasif kepada murid, guru harus memulainya dengan kalimat aktif terlebih dahulu. Kalimat dalam bahasa Inggris terpengaruh oleh tenses-nya, sedangkan kalimat dalam bahasa Indonesia tidak mengenal tenses. Oleh karena itu, murid akan merasa kesulitan dalam mengerti kalimat tersebut. 


\section{Analisis Kontrastif}

Pada dasarnya analisis kontrastif dapat dibedakan dalam beberapa bagian, secara gramatikal atau struktural, sintaksis dan pragmatis. Analisis gramatikal yaitu analisis yang berdasarkan pada tata bahasa dari masing-masing bahasa pertama dan kedua, analisis sintaksis adalah analisis yang berdasarkan pada asal kata atau bagaimana memaknai satu bahasa. Sedangkan analisis pragmatis adalah analisis yang berdasarkan pada penggunaan bahasa tersebut baik secara formal maupun informal.

Lado (1937) dan Fries (1945) mengatakan secara terpisah, yang intinya adalah bahwa agar para pengajar dapat meramalkan kesalahan yang dibuat oleh seorang pelajar, mereka haruslah mengadakan suatu analisis kontrastif antara bahasa yang dipelajari dan bahasa yang digunakan pelajar sehari-hari, khususnya dalam komponen-komponen fonologi, morfologi, kosakata dan sintaksis.

Lado (1937) mengatakan bahwa "seorang pelajar bahasa akan menemui unsur-unsur dalam bahasa kedua/asing mudah, dan unsur-unsur yang lain sangat sukar. Pelajar itu cenderung untuk mengalihkan bentuk-bentuk bahasa dan makna bentuk-bentuk tersebut serta distribusinya dan maknamaknanya dari bahasa ibu/sumbernya serta budayanya kepada bahasa kedua/asing dan budayanya baik secara produktif apabila mencoba berbicara bahasa asing itu dan berperilaku dalam budayanya, maupun secara reseptif apabila mencoba memahami dan mengerti bahasa asing dan budayanya seperti digunakan oleh para penutur aslinya.”

Fries mempunyai gagasan yang sama dengan Lado ketika ia mengatakan bahwa "materimateri instruktional yang paling efisien adalah yang berdasarkan suatu deskripsi ilmiah dari bahasa yang dipelajari, yang dibandingkan secara cermat dengan deskripsi paralel dari bahasa ibu pelajar.”

Sedangkan James (1980) berpendapat bahwa analisis kontrastif ialah suatu aktivitas linguistik yang bertujuan untuk menghasilkan tipologi dua bahasa yang kontrastif, yang berdasarkan asumsi bahwa bahasa-bahasa itu dapat dibandingkan.

\section{Prinsip Dasar Analisis Kontrastif}

Menurut Halliday (1970) terdapat dua prinsip pada analisis kontrastif, yaitu memeriksa sebelum membandingkan dan membandingkan pola-pola tertentu dan bukan bahasa secara keseluruhan. Pada prinsip pertama kita tidak dapat membandingkan cara kerja sejumlah bahasa sebelum kita memeriksa cara kerja masing-masing bahasa itu. Jika kita ingin menggunakan bahasa ibu sebagai bahan perbandingan dalam mempelajari bahasa asing, kita tidak cukup hanya bisa berbahasa ibu tetapi kita juga harus menguasai bahasa yang akan kita bandingkan itu.

Pada prinsip kedua, kita tidak dapat membandingkan bahasa Indonesia dengan bahasa Inggris secara keseluruhan. Yang dapat diperbandingkan adalah salah satu atau beberapa unsur atau pola yang terdapat pada masing-masing kalimat pasif dalam bahasa yang dibandingkan. Dan kita tidak dapat menarik kesimpulan dari kedua perbandingan ini karena setiap pola perbandingan dibahas secara terpisah. Hal ini sesuai dengan penelitian ini, yang membandingkan kalimat pasif dalam bahasa Indonesia dan bahasa Inggris.

\section{Tahap-tahap Analisis Kontrastif}

Dalam setiap perbandingan kita mengikuti tiga tahapan Anakon berikut ini: Pertama, mendeskripsikan ciri-ciri yang akan diperbandingkan dari masing-masing bahasa, yaitu memaparkan pokok bahasan secara menyeluruh yang mencakup hal arti, fungsi dan atribut dari ciri-ciri tersebut. Kedua, memastikan bahwa ciri-ciri tersebut dapat dibandingkan. Untuk itu, sebelumnya harus dapat 
diperlihatkan padanan kontekstualnya yang memungkinkan ciri itu dapat dibandingkan. Akan tetapi, bila padanan struktur itu tidak muncul dalam terjemahan, ciri-ciri itu tidak perlu diperbandingkan. Dan ketiga, setelah ciri-ciri yang akan diperbandingkan dipaparkan atau dideskripsikan dan telah jelas bahwa ciri itu dapat diperbandingkan maka langkah selanjutnya adalah membandingkan ciri-ciri dari kedua bahasa itu dengan melihat persamaan dan perbedaan di dalamnya.

\section{Kalimat Pasif dalam Bahasa Indonesia}

Kalimat aktif adalah kalimat yang subjeknya melakukan suatu tindakan. Sedangkan kalimat pasif adalah kalimat yang subjeknya menderita (dikenai suatu tindakan) dari apa yang disebutkan dalam predikatnya. Di dalam buku "Tata Bahasa Baku Bahasa Indonesia" dikemukakan pengertian aktif dan pasif dalam kalimat menyangkut beberapa hal: (1) macam verba yang menjadi predikat, (2) subjek dan objek, dan (3) bentuk verba yang dipakai. Penafsiran dalam bahasa Indonesia dilakukan dengan dua cara: (1) menggunakan verba berprefiks di- dan (2) menggunakan verba tanpa prefiks di-

Tidak semua kalimat aktif dapat dijadikan pasif. Yang dapat diubah menjadi kalimat pasif adalah kalimat aktif yang mempunyai objek. Kalimat perintah (command) dan kalimat seru (exclamation) juga tidak dapat dijadikan pasif.

Pemasifan dalam bahasa Indonesia dilakukan dengan dua cara: (1) menggunakan verba berprefiks $d i$ - dan (2) menggunakan verba tanpa prefiks di-. Jika kita gunakan simbol S untuk subjek, $\mathrm{P}$ untuk predikat, dan $\mathrm{O}$ untuk objek, maka kaidah umum untuk pembentukan kalimat pasif dari kalimat aktif dalam bahasa Indonesia adalah sebagai berikut:

Cara satu: pertukarkanlah S dengan O. Kemudian gantilah prefiks meng- dengan di- pada P. Lalu, tambahkan kata oleh di muka unsur yang tadinya S. Contoh kalimat aktif:

(i) Pak Toha mengangkat seorang asisten baru.

(ii) Ibu Gubernur akan membuka pameran itu.

(iii) Pak Saleh harus memperbaiki dengan segera rumah tua itu.

(iv) Kamu dan saya harus menyelesaikan tugas ini.

(v) Saya sudah mencuci mobil itu.

Kalimat di atas dapat diubah menjadi kalimat pasif, sebagai berikut: kalimat (1), Seorang asisten baru diangkat oleh Pak Toha. Kalimat (1) ini dapat juga dibuat: Seorang asisten baru diangkat Pak Toha. Kalimat (2), Pameran itu akan dibuka oleh Ibu Gubernur. Keberterimaan kalimat (1) dalam bentuk yang pertama dan kedua menunjukkan bahwa kehadiran bentuk oleh pada kalimat pasif bersifat manasuka. Akan tetapi, jika verba predikat tidak diikuti langsung oleh pelengkap pelaku (yang sebelumnya subjek kalimat aktif), maka bentuk oleh wajib hadir. Atas dasar itulah maka bentuk kalimat (3) berikut kita terima: kalimat (3) Rumah tua itu harus diperbaiki dengan segera oleh Pak Saleh. Sedangkan bentuk tanpa kata oleh tidak bisa diterima sebagai bentuk kalimat pasif (Rumah tua itu harus diperbaiki segera Pak Saleh). Pemasifan dengan cara pertama umumnya digunakan jika subjek kalimat aktif berupa nomina atau frasa nominal seperti contoh kalimat (1)-(5) di atas, jika subjek kalimat pasif berupa pronominal persona, padanan pasifnya umumnya dibentuk dengan cara kedua. Akan tetapi, jika subjek kalimat aktif itu berupa gabungan pronominal dengan pronominal atau frasa lain, maka padanan pasifnya dibentuk dengan cara pertama. Karena itulah bentuk kalimat pasif kalimat (4) Tugas ini harus kamu dan saya selesaikan, yang dibentuk dengan cara kedua, kita tolak sebagai bentuk pasif kalimat (4) di atas. Kehadiran kata oleh pada kalimat (4) adalah wajib, jadi kalimat pasif yang berterima dari kalimat (4) adalah Tugas itu harus diselesaikan oleh kamu dan saya.

Cara dua: padanan pasif dari kalimat aktif transitif yang subjeknya berupa pronominal dibentuk dengan cara kedua. Adapun kaidah pembentukan kalimat pasif cara kedua itu adalah: 
pertama pindahkan O ke awal kalimat. Lalu, tanggalkan prefiks meng- pada P. Kemudian, pindahkan $\mathrm{S}$ ke tempat yang tepat sebelum verba.

Cara dua ini bila diterapkan pada contoh kalimat (5), bentuk kalimat pasifnya adalah 'Mobil itu sudah saya cuci'. Jika subjek kalimat aktif transitif berupa pronominal persona ketiga atau nama diri yang relatif pendek, maka padanan pasifnya dapat dibentuk dengan cara pertama atau kedua sepeti tampak pada contoh berikut:

(i) Aktif: Mereka akan membersihkan ruangan ini.

Pasif 1: Ruangan ini akan dibersihkan (oleh) mereka.

Pasif 2: Ruangan ini akan mereka bersihkan.

(ii) Aktif : Dia sudah membaca buku itu.

Pasif 1: Buku itu sudah dibaca olehnya/ (oleh) dia.

Pasif 2: Buku itu sudah dibacanya/ dia baca.

(iii) Aktif : Ayah belum mendengar berita duka itu.

Pasif 1: Berita duka itu belum didengar (oleh) ayah.

Pasif 2: Berita duka itu belum ayah dengar.

Apabila subjek kalimat aktif transitif itu panjang, maka padanan kalimat pasifnya dibentuk dengan cara pertama. Jadi, bentuk seperti Berita duka itu belum didengar oleh Susilowati tidak dapat diubah menjadi Berita duka itu belum Susilowati dengar.

Pembentukan kalimat pasif dengan cara dua dari kalimat aktif transitif yang subjeknya berupa pronominal persona ketiga atau nama diri pada umumnya terbatas pada pemakaian sehari-hari. Pronomina $a k u$, engkau, dan dia (yang mengikuti predikat) pada kalimat pasif cenderung dipendekkan menjadi ku-, kau-, dan -nya seperti pada contoh kalimat berikut:

a.1. Surat itu baru $a k u$ terima kemarin

a.2. Surat itu baru kuterima kemarin.

b.1. Buku ini perlu engkau baca.

b.2. Buku ini perlu kaubaca.

c.1. Pena saya dipinjam oleh dia.

c.2. Pena saya dipinjam olehnya.

Perubahan kalimat aktif transitif yang mengandung kata seperti ingin atau mau cenderung menimbulkan pergerseran makna. Contoh: Andi ingin mencium Tuti. Tuti ingin dicium Andi. Pada kalimat pertama adalah kalimat aktif, jelas bahwa yang ingin melakukan perbuatan mencium adalah Andi, tetapi pada kalimat kedua, orang cenderung menafsirkan bahwa yang menginginkan ciuman itu adalah Tuti dan bukan Andi. Tafsiran makna kalimat pasif yang berbeda dengan makna padanan kalimat aktif itu timbul karena kodrat kata ingin yang cenderung dikaitkan dengan unsur di sebelah kiri yang mendahuluinya. Hal ini tampak lebih nyata pada keganjilan pasangan kalimat 'Andi ingin mencuci mobilnya' - 'Mobilnya ingin dicuci Andi'.

Arti pasif dapat pula bergabung dengan unsur lain seperti unsur ketaksengajaan. Jika kalimat aktif diubah menjadi kalimat pasif dan dalam kalimat pasif itu terkandung pula pengertian bahwa perbuatan yang dinyatakan oleh verba itu mengandung unsur yang tak sengaja, maka bentuk prefiks yang dipakai untuk verba bukan lagi di-, melainkan ter-. Perhatikan perbedaan kalimat (1) dan kalimat (2) yang berikut ini:

(1) a. Penumpang bus itu dilempar ke luar.

(1) b. Penumpang bus itu terlempar ke luar.

(2) a. Dia dipukul kakaknya.

(2) b. Dia terpukul kakaknya. 
Kalimat (1a dan 2a) menunjukkan bahwa seseorang melakukan perbuatan itu dengan niat dan kesengajaan. Sebaliknya, kalimat (1b dan 2b) mengacu ke suatu keadaan atau ke ketidaksengajaan si pelaku perbuatan. Pada kalimat (1b) mungkin saja penumpang tadi terlempar oleh orang lain, atau mungkin juga oleh guncangan bus yang terlalu besar.

Di samping makna ketaksengajaan itu, verba pasif yang memakai ter- juga dapat menunjukkan kekodratan. Artinya, kita tidak memasalahkan siapa yang melakukan perbuatan tersebut sehingga seolah-olah sudah menjadi kodratlah bahwa sesuatu harus demikian keadaannya. Perhatikan contoh kalimat berikut:

(A) Gunung Merapi terletak di Pulau Jawa.

(B) Soal ini terlepas dari rasa senang dan tidak senang.

Pada contoh (A) dan (B) tidak ada unsur sengaja atau tidak sengaja, dan kita pun tidak memasalahkan siapa yang meletakkan gunung itu atau yang melepaskan soal ini. Bentuk kalimat pasif lain yang bermakna adversatif tampak pada contoh berikut:

(C) 1. Soal itu diketahui oleh orang tuanya.

(C) 2. Soal itu ketahuan oleh orang tuanya.

(D) 1. Partai kita dimasuki unsur kiri.

(D) 2. Partai kita kemasukkan unsur kiri.

Di sini perlu ditekankan bahwa makna kalimat yang predikatnya memakai ke-an ini adalah pasif dengan tambahan makna adversatif, yakni makna yang tidak menyenangkan.

\section{Kalimat Pasif dalam Bahasa Inggris}

Dalam kalimat pasif, objek dari kalimat aktif menjadi subjek kalimat pasif. Kata kerja dalam kalimat pasif dalam bahasa Inggris selalu menggunakan to be dengan past participle (= kata kerja bentuk ketiga: to do - did - done)

Berikut ini adalah beberapa jenis kalimat pasif dalam bahasa Inggris.

Kalimat pasif yang pelakunya (doer, agent) tidak dikenal. Contoh:

Passive: One of our windows was broken.

Active: Someone broke one of our windows.

Kalimat pasif yang pelakunya tidak jelas atau tidak penting. Contoh:

Passive: English is spoken all over the world

Active: People of all over the world speak English.

Kalimat pasif yang pelakunya diketahui atau diberi tekanan. Contoh:

Passive: The fish is being eaten by the cat

Active: The cat is eating the fish.

Kalimat aktif dan pasif dapat dibuat sebanyak tenses yang ada. Apabila kita mengubah kalimat aktif menjadi pasif atau sebaliknya, kita tidak boleh mengubah tenses-nya. Dengan kata lain, tenses kalimat aktif dan pasif harus sama. Perhatikan contoh berikut.

Simple Present: Mary helps John $\rightarrow$ John is helped by Mary

Present Progressive: Mary is helping John $\rightarrow$ John is helping by Mary

Present Perfect: Mary has helped John $\rightarrow$ John has been helped by Mary

Simple Past: Mary helped John $\rightarrow$ John was helped by Mary

Past Progressive: Mary was helping John $\rightarrow$ John was being helped by Mary

Past Perfect: Mary had helped John $\rightarrow$ John had been helped by Mary

Simple Future: Mary will helped John $\rightarrow$ John will be helped by Mary 
Be going to: Mary is going to help John $\rightarrow$ John is going to be helped by Mary

Future Perfect: Mary will have helped John $\rightarrow$ John will have been helped by Mary

Bentuk kata kerja to be-verb -ed yang kita kenal sebagai bentuk kalimat pasif tidak selalu menunjukkan suatu perbuatan, melainkan ada yang menunjukkan suatu keadaan. Contoh kalimat pasif yang menunjukkan perbuatan: The door was opened by a thief by force. Contoh kalimat pasif yang menunjukkan keadaan: The small child is already bored with his new toy.

\section{Perbandingan Kalimat Pasif dalam Bahasa Inggris dan Bahasa Indonesia}

Dalam bahasa Inggris kata kerja dalam kalimat pasif mempunyai beragam bentuk sesuai dengan "tenses"-nya. Secara umum, rumus bentuk tersebut bisa disimpulkan sebagai - kata kerja bantu (auxiliary verb) be + past participle. Kata kerja utama (main verb) dalam kalimat pasif harus berbentuk past participle. Dalam kalimat pasif, subjek kata kerja adalah objek pada kalimat aktif yang berarti bahwa subjek yang sebenarnya bukan pelakunya, ia hanya subjek kalimat. Dalam kalimat pasif, pelakunya diungkapkan dengan frasa "oleh...”. Namun frasa tersebut boleh dihilangkan karena sudah jelas siapa pelaku kata-kerja tersebut.

Kata kerja pasif bahasa Inggris diterjemahkan ke dalam bahasa Indonesia dengan menggunakan awalan di- atau ter- di depan kata kerja. Awalan ter- mempunyai makna konotasi bahwa perbuatan tersebut tidak disengaja. Contohnya: "The child was struck by a car"; terjemahannya: "Anak itu tertabrak oleh mobil”. Dalam kalimat itu, biasanya mobil tidak dengan sengaja menabrak seorang anak. Hal itu terjadi karena ketidaksengajaan. Ada kalanya penerjemahan ke dalam bahasa Indonesia tidak dalam kalimat pasif, inilah yang akan membuat siswa kesulitan dalam membedakan mana yang harus diartikan di-, ter- atau tidak keduanya. Kembali lagi siswa perlu tahu maksud dan tujuan kalimat tersebut digunakan dan kapan digunakan.

Kalimat pasif dalam bahasa Indonesia dilihat dari strukturnya menggunakan di-, ter- ataupun $k e-$, yang dalam bahasa Inggris hanya mengenal to be + past participle yang tergantung waktu kejadian (sesuai tenses).

\section{SIMPULAN}

Seperti dalam bahasa Indonesia, Bahasa Inggris pun terdapat kalimat pasif. Kalimat pasif ini digunakan untuk mengungkapkan kejadian yang menimpa subyeknya. Setelah dianalisis dan dicari padanan dan perbandingannya dalam kalimat pasif dalam bahasa Indonesia dan Bahasa Inggris, penulis telah menemukan persamaan dan perbedaan yang ada. Baik persamaan maupun perbedaannya dapat dilihat secara struktural maupun secara pragmatis. Secara struktural terdapat persamaan kalimat pasif dalam Bahasa Indonesia dan Bahasa Inggris yaitu subyeknya yang dikenai tindakan dan obyeknya sebagai pelaku yang ditandai dengan kata by, dalam Bahasa Indonesia juga demikian, subyeknya yang dikenai tindakan dan obyeknya sebagai pelaku yang ditandai oleh kata "oleh". Sedangkan perbedaannya adalah dalam Bahasa Indonesia tidak mengenal perbedaan waktu pengucapan. Dalam bahasa Inggris, kalimat pasif diucapkan sama meskipun kalimat ini diucapkan sekarang (present), masa depan (future), ataupun masa lalu (past). Kata kerja yang digunakan dalam masing-masing tenses berbeda karena perbedaan waktu, sedangkan dalam bahasa Indonesia tidak ada perbedaan penggunaan kata kerja. Secara pragmatis, makna yang terkandung di dalam kalimat pasif bahasa Inggris sama dengan makna yang terkandung dalam bahasa Indonesia, yaitu sama-sama menyatakan obyek sebagai pelaku dan subyek sebagai penerima tindakan (yang dikenai tindakan). Perbedaannya terletak pada makna adversatif dan ketidaksengajaan. Dalam bahasa Inggris tidak terdapat kalimat pasif yang bermakna ketidaksengajaan. 


\section{DAFTAR PUSTAKA}

Azar, B. S. (1989). Understanding and Using English Grammar. New Jersey: Prentice-Hall, Inc.

Halliday, M.A.K. (1970). The Linguistic Sciences and Language Teaching. Bloomington: Indiana University Press.

Hasibuan, S. R. (1991). Teori Terjemahan dan Kaitannya dengan Tata Bahasa Inggris. Jakarta: Dian Rakyat.

James, C. (1980). Contrastive Analysis. England: Longman.

Keraf , G. (1991). Tata Bahasa Indonesia. Jakarta: Nusa Indah.

Lado, R. (1964). Linguistic Across Culture. Michigan: University of Michigan Press.

Tarigan, H. G. (1992). Pengajaran Analisis Kontrastif Bahasa. Bandung: Penerbit Angkasa. 